\title{
Chapter 6 \\ Interrelationships Among Timing of Hibernation, Reproduction, and Warming Soil in Free-Living Female Arctic Ground Squirrels
}

\author{
Cory T. Williams, Michael J. Sheriff, Franziska Kohl, \\ Brian M. Barnes and C. Loren Buck
}

\begin{abstract}
The effects of climate change on hibernating species will depend, in part, on their responsiveness to environmental cues used to adjust the seasonal timing of annual events of hibernation and reproduction. Using long-term data collected from two arctic ground squirrel populations living $20 \mathrm{~km}$ apart in northern Alaska, we investigate the relationships between the timing of hibernation and reproduction and, in addition, the potential for change in soil temperatures to act as a proximate cue. Previously, we found that female ground squirrels living at the southern-most site, Atigun River, emerge from hibernation and give birth 13 days earlier than females at Toolik Lake. Here we show that timing of parturition was tightly linked to the termination of heterothermy and subsequent emergence from the hibernacula at both sites, whereas timing of entrance into hibernation was only weakly correlated with date of parturition in Toolik Lake females. Females ended heterothermy in spring coincident with rising soil temperatures from winter minima, but since average soil temperatures did not differ between the two sites, a single threshold in warming cannot explain the differences in timing of spring emergence and reproduction between the two populations. Earlier reproduction at Atigun is associated with earlier snowmelt, yet, how this is achieved and the relative importance of phenotypic plasticity versus genetic differences between the two populations will require further investigation.
\end{abstract}

\footnotetext{
C. T. Williams · C. Loren Buck ( $₫)$

Department of Biological Sciences, University of Alaska Anchorage,

Anchorage, AK 99508, USA

e-mail: loren@uaa.alaska.edu

C. T. Williams

Department of Biological Sciences, University of Alberta, Edmonton,

AB T6G 2E9, Canada
}

M. J. Sheriff · F. Kohl · B. M. Barnes

Institute of Arctic Biology, University of Alaska Fairbanks,

902 N. Koyukuk Dr., Fairbanks, AK 99775, USA 


\subsection{Introduction}

The arctic environment has long, cold winters and correspondingly short growing seasons that severely limit the time available each year for reproduction and growth of locally breeding animals. Climate warming is predicted to lengthen the growing season, particularly at high latitudes (Serreze and Francis 2006; Post et al. 2009), which provides increased foraging opportunities. However, biological interactions can also be disrupted due to intra- and inter-specific variability in the response to climate forcing (Høye et al. 2007). The response of species to changing seasonality depends on the rate at which populations evolve through natural selection and also on the ability of individuals to respond, via physiological mechanisms, to environmental cues that are indicative of changes in the growing season (Berteaux et al. 2004). Arctic migrants, for example, may not be capable of appropriately adjusting the timing of reproduction to match shifts in local resource status because cues used to fine-tune their migration may not reflect the conditions of the breeding grounds (e.g., Post and Forchhammer 2008).

As a year-round resident, arctic ground squirrels (Urocitellus parryii) overwinter on their breeding grounds. The capacity of individuals to respond adaptively to environmental change will depend on their phenotypic plasticity and the reliability of the cues used to align their annual timing of hibernation and reproduction with the local environment, since the environment within their underground hibernacula may not be reflective of changing conditions on the surface. As part of ongoing efforts to better understand how changes in seasonality impact the physiological and population ecology of arctic mammals, Sheriff et al. (2011) compared phenologies of hibernation and reproduction in arctic ground squirrels living at two sites in northern Alaska with different snow cover regimes. One study site located near the Atigun River, approximately $20 \mathrm{~km}$ south of the second site at Toolik Lake, becomes snowfree 27 days earlier in spring and becomes snow covered 17 days later in autumn. Timing of hibernation and reproduction of arctic ground squirrels at the Atigun site occurs 13 days earlier than at Toolik Lake, and we suggested that this variation in phenology likely reflects phenotypic plasticity generated via physiological mechanisms which provide individuals the ability to respond to changes in their environment (Sheriff et al. 2011).

Seasonal timing of hibernation and reproduction are under strong endogenous control in hibernating ground squirrels; however, the precise timing or fine-tuning of annual events reflects responsiveness to the local environment. The environmental cues used for hibernation and reproduction are not known, although snow cover and air temperature have previously been implicated as contributing factors in ground squirrels (Murie and Harris 1982; Michener 1992) and other hibernators (Ozgul et al. 2010). However, while squirrels are exposed to these factors following their spring emergence, information about current snow cover and ambient above-ground temperature is unlikely to be available to animals sequestered within hibernacula. Of cues available to hibernating ground squirrels, we propose that changes in soil temperature will be the most available and relevant to 
seasonal timing. During hibernation arctic ground squirrels are highly responsive to changes in soil temperature. Body temperature $\left(T_{\mathrm{b}}\right)$ during torpor closely tracks surrounding soil temperatures until the active layer freezes and cools below $-3.0^{\circ} \mathrm{C}$ (e.g., Williams et al. 2011a). Mean $\left(-8.9^{\circ} \mathrm{C}\right)$ and minimum $\left(-25^{\circ} \mathrm{C}\right)$ soil temperatures across most of the heterothermic period are below minimum body temperature $\left(T_{\mathrm{b}}:-2.9^{\circ} \mathrm{C}\right)$ indicating squirrels are highly thermogenic and responsive to changes in soil temperature for most of the hibernation season (Barnes 1989; Buck and Barnes 1999a; Williams et al. 2012).

Here, we use the long-term data set described by Sheriff et al. (2011) to examine how the timing of the ending of heterothermy (torpor and arousal cycles) and emergence from hibernation relates to the timing of reproduction in arctic ground squirrels. Further, since there are overall differences in snow cover between the two sites, we examine whether they differ in either the average temperature of the soil or in the rate at which the soil warms as such differences may explain observed variance in the timing of spring emergence.

\subsection{Methods}

\subsubsection{Study Species}

With a body mass as great as $1.5 \mathrm{~kg}, U$. parryii is the largest New World ground squirrel and is distributed across northern Alaska, Canada, and eastern Siberia. Their annual cycle includes a 3-5 month season of above-ground activity (Buck and Barnes 1999b; Williams et al. 2012), with breeding beginning in mid to late April shortly after females emerge from hibernation (Buck and Barnes 2003). Young are born in mid to late May, appear above ground shortly before weaning in mid to late June, and disperse 2-3 weeks after first appearing on the surface (Lacey 1991). Adult females enter hibernation as early as late July and young of the year and males enter in September. Animals spend the remaining 7-9 months of the year sequestered in frozen burrow systems (hibernacula), alternating between long (2-3 weeks) bouts of torpor and shorter $(10-20 \mathrm{~h})$ intervals of high body temperature during interbout arousal and euthermia (Buck et al. 2008). Hibernaculum depth is limited to ca. $1 \mathrm{~m}$ because the arctic tundra is underlain by a continuous permafrost layer that is an impenetrable barrier (Buck and Barnes 1999a).

\subsection{Field Measurements}

We determined the timing of annually recurring life-cycle events (termination of heterothermy, spring emergence, parturition, entrance into hibernation, and initiation of heterothermy) from patterns of core $T_{\mathrm{b}}$ recorded using data-loggers 
implanted in free-living arctic ground squirrels, as described in Williams et al. (2011b). Each spring, ground squirrels were implanted/explanted with abdominal temperature loggers (modified TidBit Stowaway model TBICU32-05 + 44, accuracy of $\pm 0.2^{\circ} \mathrm{C}$, Onset Computer Corporation, Pocasset, MA) programmed to record $T_{\mathrm{b}}$ at 20-min intervals for up to 18 months (Long et al. 2007). Annual records of $T_{\mathrm{b}}$ were collected from 1999 to 2010 at a study site near Toolik Lake $\left(68^{\circ} 38^{\prime} \mathrm{N}, 149^{\circ} 38^{\prime} \mathrm{W}\right)$ and from 2003 to 2010 at a site $20 \mathrm{~km}$ to the south near Atigun River $\left(68^{\circ} 27^{\prime} \mathrm{N}, 149^{\circ} 21^{\prime} \mathrm{W}\right)$; physical and ecological site characteristics are described in Sheriff et al. (2011). Animal protocols were approved by the University of Alaska Fairbanks Institutional Animal Care and Use Committee and the Department of Defense Animal Care and Use Review Office.

Here, we restrict our analyses to the timing of hibernation, conception, and parturition in females known to have given birth; the day of parturition can be determined from an abrupt upward shift in $T_{\mathrm{b}}$ (Williams et al. 2011b), and the day of conception was estimated by subtracting an average gestation length of 25 days (Lacey 1991) from the date of parturition. Final sample sizes for the date females terminated heterothermy and emerged in spring were 22 (Toolik Lake) and 19 (Atigun River) and for dates of fall immergence and initiation of heterothermy were 24 (Toolik Lake) and 20 (Atigun River).

We recorded soil temperature once every $6 \mathrm{~h}$ at $-1 \mathrm{~m}$ depth adjacent to 33 burrow entrances (17 Toolik; 16 Atigun) beginning in fall 2009 with data loggers (Hobo Temp II, Onset Computer Corporation; accuracy $\pm 0.16^{\circ} \mathrm{C}$ at the ice point).

\subsection{Statistical Analyses}

Relationships between the timing of annually recurring life-history events were examined using Pearson's product moment correlation analysis. As we were interested in the potential of conditions within the hibernacula to affect the timing of spring emergence, we restricted our analyses of soil temperature data from April 1 to May 20, a range which encompasses the earliest observed end date for heterothermy in females (April 13) and the latest observed date of emergence (May 18; Sheriff et al. 2011). We compared soil temperatures between sites using repeated-measures mixed models with average temperature (binned in 10-day increments) as the dependent variable. Use of mixed models permitted the inclusion of two burrows lacking $T_{\mathrm{h}}$ data for the final time interval. Means are reported \pm SD.

\subsection{Results}

In females, the date of parturition was highly correlated with the date of termination of heterothermy (Fig. 6.1; both sites combined: $r=0.87, P<0.0001$; Toolik: $r=0.77, P<0.0001$; Atigun: $r=0.88, P<0.001)$. The correlation 
Fig. 6.1 Relationship between timing of parturition and (a) last day of heterothermy, (b) date of emergence, and (c) date of subsequent immergence into the hibernacula
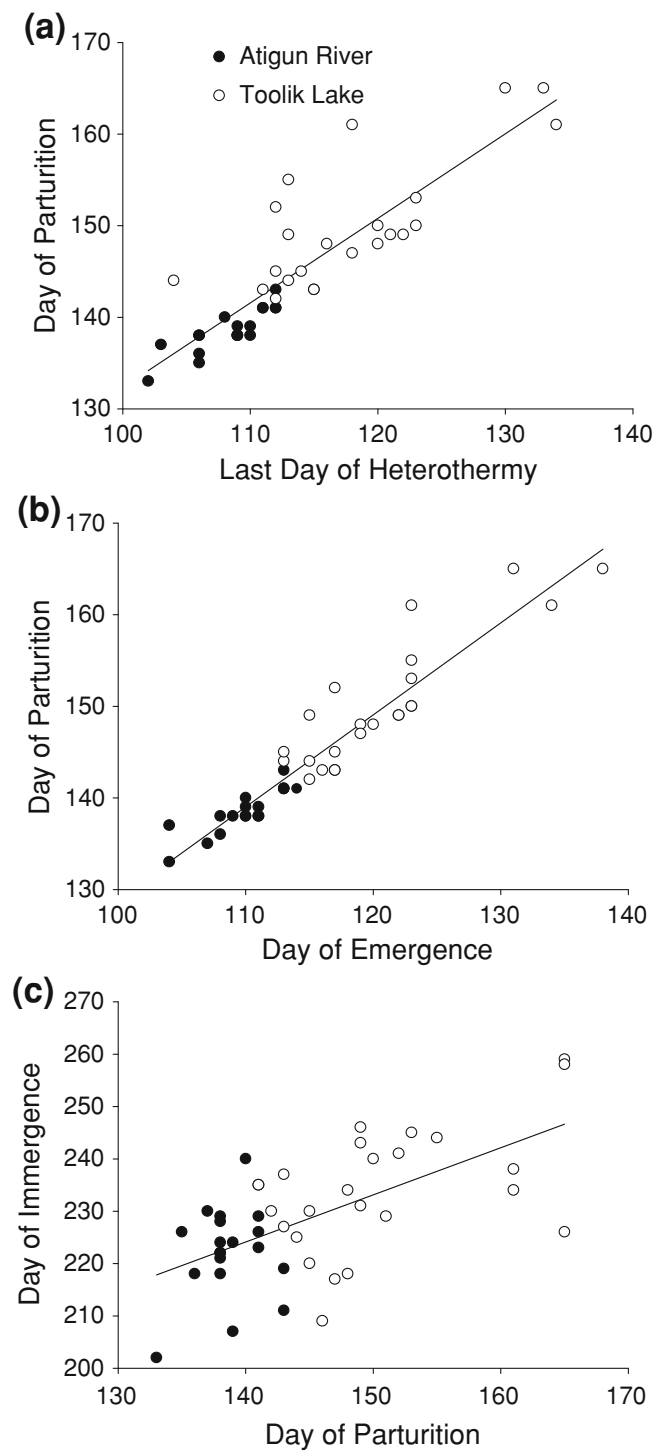

coefficient between dates of parturition and emergence was even higher (both: $r=0.94, \quad P<0.0001$; Toolik: $r=0.88, \quad P<0.0001$; Atigun: $r=0.89$, $P<0.001)$, as the latency between emergence of females and subsequent courtship and impregnation is brief. Females emerged $2.2 \pm 2.2$ days (Atigun: $1.5 \pm 0.9$ days; Toolik: $2.9 \pm 2.9$ days) after they terminated heterothermy and were impregnated $4.0 \pm 2.7$ days following emergence (Atigun: $3.4 \pm 1.5$ days; Toolik $4.7 \pm 3.3$ days). The date of entrance into hibernation in fall was correlated with the date of parturition only in Toolik females (both: $r=0.62$, $P<0.0001$; Toolik $r=0.53, P=0.008$; Atigun $r=0.25, P=0.29$ ). 


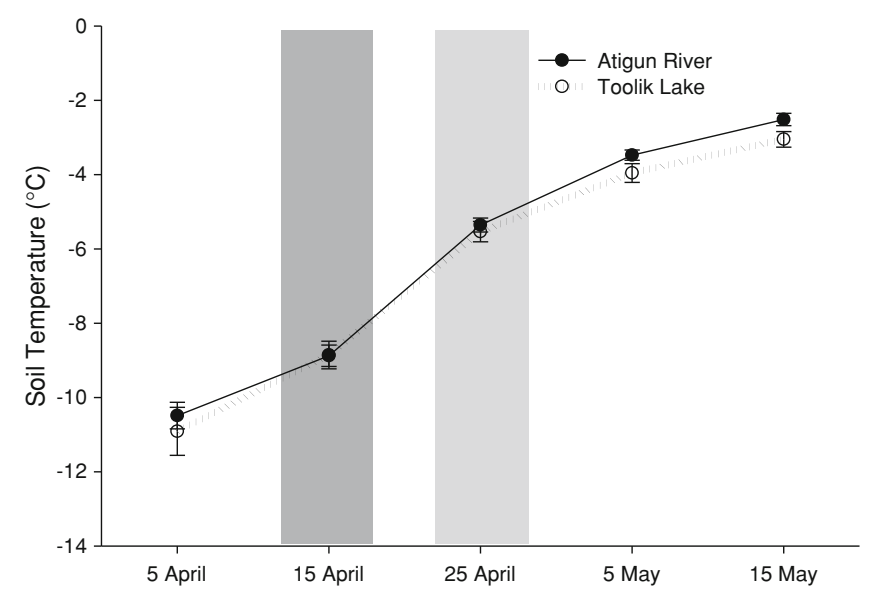

Fig. 6.2 Mean ( \pm SE) soil temperatures, binned in 10-day increments, measured from burrows at a site near Toolik Lake (dashed line; $n=17$ ) and Atigun River (solid line; $n=16$ ) in 2010. Dark and light gray-shaded portions of the figure indicate the range of dates reproductive females terminated heterothermy at Atigun River and Toolik Lake in 2010, respectively

Across all years, females from Atigun were earlier than females from Toolik in the date they ended heterothermy (9 days earlier), emerged (11 days), gave birth (11 days), entered the hibernacula (11 days), and began heterothermy anew (12 days). In 2010, the year for which we have soil temperature data, females displayed a similar pattern of phenology as the average across all years: Atigun females ended heterothermy (10 days), emerged (11 days), gave birth (11 days), entered the hibernacula (11 days), and began heterothermy anew (12 days) earlier than their Toolik counterparts. Soil temperatures in 2010 became significantly warmer as spring progressed $\left(\mathrm{F}_{4,30}=174.8 ; P<0.0001\right)$, but did not differ between Atigun and Toolik $\left(\mathrm{F}_{1,30}=1.2 ; P=0.3\right)$ and the interaction between site and date was not significant $\left(\mathrm{F}_{4,30}=2.1 ; P=0.1 ;\right.$ Fig. 6.2$)$, indicating that it did not begin to warm sooner at Atigun. However, Atigun females ended heterothermy between 12 and 19 April 2010, an interval that coincided with when soil temperatures first began to warm from their winter minima. Toolik females ended heterothermy between 22 and 28 April 2010, as soil temperatures continued to warm.

\subsection{Discussion}

The ability of organisms to modulate seasonal timing of annually recurring lifehistory events to remain in synchrony with shifts in their environment depends, in part, on the environmental cues available and used to adjust timing. Previously, we reported that the phenology of hibernation and reproduction in free-living arctic 
ground squirrels varies greatly over a relatively small spatial scale and that this variation corresponds with differences in the duration of snow cover (Sheriff et al. 2011). Presently, we show that the timing of parturition in female arctic ground squirrels is tightly correlated with the date females end heterothermy and begin daily activity on the surface in spring. Females remain below ground after ending heterothermy for a short duration ( $\sim 2$ days), emerge, and then mate within $\sim 4$ days. Considering that squirrels sequestered within their hibernacula presumably lack information about surface conditions, we examined whether soil warming might be the proximate cue used to adjust spring hibernation and thus reproductive phenology. Although warming of soil generally coincided with the timing of female emergence, we found no simple differences in patterns of soil temperatures between sites that explained the 12-day difference in dates of parturition. Whether females are utilizing other environmental cues to adjust their phenology remains unknown.

\subsection{Timing of Reproduction}

The timing of reproduction poses a fundamental challenge for animals that occupy regions characterized by short growing seasons. Although timing of hibernation and reproduction in ground squirrels are known to be under endogenous control (Kenagy 1980), there is also a likely interplay with cues from the local environment (Visser et al. 2010). If spring conditions occur earlier it will likely benefit animals to advance the timing of their breeding to either maximize the amount of time available for offspring growth and development or to match energy demand with an earlier availability of adequate food (Visser and Both 2005). However, animals can only do so if the cues they use to time these annual events are reliable indicators of the current environment and are anticipatory of future conditions.

The phenology of many migrant and hibernating species has advanced at some locales in response to warming, although the magnitude of the advance does not always match the shift in timing of resource availability (Inouye et al. 2000). For example, in caribou the earlier timing of migration in spring has not kept pace with the seasonal advancement in plant growth and this may be contributing to the decline in reproduction (Post and Forchhammer 2008). In arctic ground squirrels, the high correlation between the date of parturition and the date of emergence indicates females will only be able to appropriately adjust reproductive timing if they are able to terminate hibernation earlier when conditions warrant. Parturition was better correlated with the date of emergence than the end of heterothermy (Fig. 6.1), as some females remained below ground for an extended period (up to 12 days) after resumption of euthermia. These extended below ground periods were rare in females, and occurred only at Toolik, the site characterized by late and more variable snowmelt.

We also found that the timing of parturition was correlated with the subsequent date of entrance into hibernation, although this effect was relatively weak and 
driven solely by females at Toolik Lake that give birth late in the spring. Females that emerge, give birth, and wean later may be forced to slightly delay their impending hibernation until they gain sufficient mass for overwintering. Fitness consequences of delayed breeding remain unclear, as in late summer the ground remains snow-free and access to food does not appear to be limiting when adult females enter hibernation in late July and August. Late-borne offspring will encounter reduced foraging opportunities, however, if their active season extends through September when freezing temperatures and snow become widespread. Offspring born earlier in spring, in contrast, might be able to achieve a larger body mass which could improve over-winter survival rates (e.g., Ozgul et al. 2010). In other species, females that give birth later tend to have decreased weaning success (e.g. Réale et al. 2003; Broussard et al. 2008), which might explain the relatively weak relationship between timing of reproduction and fall immergence. If females that breed late do not wean their offspring they may enter hibernation sooner than expected having the ability to increase body mass earlier due to the loss of their litter. However, we were unable to determine whether females which bred late were successful or not in our study. We expect that weaning success along with timing of breeding may be major factors affecting the timing of immergence in females.

\subsection{Phenotypic Plasticity Versus Genetic Variability}

Whether differences in the timing of spring emergence, and consequently parturition, are driven by phenotypic plasticity in response to environmental cues or are reflective of genetic differences between the two populations remains unclear. Lane et al. (2011) demonstrated that timing of emergence from hibernation was a heritable trait in a population of Columbia ground squirrels (Urocitellus columbianus); however, the additive genetic variance component explained only about $20 \%$ of the total phenotypic variation in this trait. We suggest that some of the additional variance can be attributed to phenotypic plasticity in response to local conditions. One possibility is that females do respond to shifts in ambient temperature within the hibernacula (i.e., soil temperature), but the response to temperature differs between sites. This could occur if females from Toolik have a different soil temperature threshold that triggers the end of heterothermy relative to Atigun females. In this case interannual variation in timing of emergence and reproduction may be explained by variation in soil temperature within each site but not between sites. We are currently investigating this possibility.

Another possibility is that female arctic ground squirrels move out of the insulated "nest" chamber during brief arousal bouts of euthermia and assess snow conditions from burrow entrances. Buck et al. (2008) noted that the penultimate arousal interval is significantly longer than earlier intervals, which suggests that behavior and/or physiology is different during the brief interbout arousals later in hibernation. This shift in behavior/physiology may reflect an endogenously driven 
seasonal shift in sensitivity to environmental cues. Finally, it is possible that timing of female emergence is dictated primarily by date of entry into hibernation, as Sheriff et al. (2011) found no significant difference in the duration of hibernation between Toolik and Atigun females. However, there was substantial variation in the duration of hibernation among individuals (range: 200-271 days) making this an unlikely possibility. Patterns of hibernation are without a doubt under strong endogenous control but the degree to which females are capable of altering these patterns in response to environmental change, particularly with respect to the termination of hibernation, remains unclear. Therefore, the capacity of this species to respond to environmental changes predicted by climate models also remains uncertain.

Acknowledgments Funding was provided by the National Science Foundation (EF-0732763 and -0732755) to CLB and BMB and the US Army Medical Research and Materiel Command Grant \#05178001 to BMB. We thank Trixie Lee and Melanie Richter for their invaluable help in gathering field data.

\section{References}

Barnes BM (1989) Freeze avoidance in a mammal: body temperatures below $0^{\circ} \mathrm{C}$ in an arctic hibernator. Science 244:1593-1595

Berteaux D, Réale D, McAdam AG, Boutin S (2004) Keeping pace with fast climate change: can arctic life count on evolution? Integr Comp Biol 44:140-151

Broussard DR, Dobson FS, Murie JO (2008) Previous experience and reproductive investment of female Columbian ground squirrels. J Mammal 89:145-152

Buck CL, Barnes BM (1999a) Temperatures of hibernacula and changes in body composition of arctic ground squirrels over winter. J Mammal 80:1264-1276

Buck CL, Barnes BM (1999b) Annual cycle of body composition and hibernation in free-living arctic ground squirrels. J Mammal 80:430-442

Buck CL, Barnes BM (2003) Androgen in free-living arctic ground squirrels: seasonal changes and influence of staged male-male aggressive encounters. Horm Behav 43:318-326

Buck CL, Breton A, Kohl F, Tøien Ø, Barnes BM (2008) Overwinter body temperature patterns in free-living arctic squirrels (Spermophilus parryii). In: Lovegrove BG, McKechnie AE (eds) Hypometabolism in animals: torpor hibernation and cryobiology. University of KwaZulu-Natal, Pietermaritzburg, pp 317-326

Høye TT, Post E, Meltofte H, Schmidt NM, Forchhammer MC (2007) Rapid advancement of spring in the High Arctic. Curr Biol 17:R449-R451

Inouye DW, Barr B, Armitage KB, Inouye BD (2000) Climate change is affecting altitudinal migrants and hibernating species. Proc Natl Acad Sci 97:1630-1633

Kenagy GJ (1980) Interrelation of endogenous annual rhythms of reproduction and hibernation in the golden-mantled ground squirrel. J Comp Physiol A 135:333-339

Lacey EA (1991) Reproductive and dispersal strategies of male Arctic ground squirrels (Spermophilus parryii plesius). $\mathrm{PhD}$ thesis, University of Michigan

Lane JE, Kruuk LEB, Charmantier A, Murie JO, Coltman DW, Buoro M, Raveh S, Dobson FS (2011) A quantitative genetic analysis of hibernation emergence date in a wild population of Columbian ground squirrels. J Evol Biol 24:1949-1959

Long RA, Hut RA, Barnes BM (2007) Simultaneous collection of body temperature and activity data in burrowing mammals: a new technique. J Wildl Manage 71:1375-1379 
Murie JO, Harris MA (1982) Annual variation of spring emergence and breeding in Columbian ground squirrels (Spermophilus columbianus). J Mammal 63:431-439

Ozgul A, Childs DZ, Oli MK, Armitage KB, Blurnstein DT, Olson LE, Tuljapurkar S, Coulson T (2010) Coupled dynamics of body mass and population growth in response to environmental change. Nature 466:482-485

Post E, Forchhammer MC (2008) Climate change reduces reproductive success of an arctic herbivore through trophic mismatch. Phil Trans R Soc B 363:2367-2373

Post E, Forchhammer MC, Bret-Harte MS, Callaghan TV, Christensen TR, Elberling B, Fox AD, Gilg O, Hik DS, Høye TT, Ims RA, Jeppesen E, Klein DR, Madsen J, McGuire AD, Rysgaard S, Schindler DE, Stirling I, Tamstorf MP, Tyler NJC, van der Wal R, Welker J, Wookey PA, Schmidt NM, Aastrup P (2009) Ecological dynamics across the Arctic associated with recent climate change. Science 325:1355-1358

Réale D, McAdam AG, Boutin S, Berteaux D (2003) Genetic and plastic responses of a northern mammal to climate change. Proc Roy Soc B 270:591-596

Serreze MC, Francis JA (2006) The Arctic amplification debate. Clim Change 76:241-264

Sheriff MJ, Kenagy GJ, Richter M, Lee T, Tøien Ø, Kohl F, Buck CL, Barnes BM (2011) Phenological plasticity: variation in annual timing of hibernation and breeding in two nearby populations of arctic ground squirrels. Proc Roy Soc B 278:2369-2375

Visser ME, Both C (2005) Shifts in phenology due to global climate change: the need for a yardstick. Proc Roy Soc B 272:2561-2569

Visser ME, Caro SP, van Oers K, Shaper SV, Helm B (2010) Phenology, seasonal timing and circannual rhythms: towards a unified framework. Proc Roy Soc B 365:3113-3127

Williams CT, Goropashnaya AV, Buck CL, Fedorov VB, Kohl F, Lee TN, Barnes BM (2011a) Hibernating above the permafrost: effects of ambient temperature and season on expression of metabolic genes in liver and brown adipose tissue of arctic ground squirrels. J Exp Biol 214:1300-1306

Williams CT, Sheriff MJ, Schmutz JA, Kohl F, Tøien Ø, Buck CL, Barnes BM (2011b) Data logging of body temperatures provides precise information on phenology of reproductive events in a free-living arctic hibernator. J Comp Physiol B 181:1101-1109

Williams CT, Barnes BM, Buck CL (2012) Body temperature rhythms persist under the midnight sun but are absent during hibernation in free-living arctic ground squirrels. Biol Lett 8:31-34. doi:10.1098/rsbl.2011.0435 